University of Wollongong

Research Online

Faculty of Engineering - Papers (Archive)

Faculty of Engineering and Information

Sciences

$1-6-2001$

\title{
Laboratory measurement of two-phase flow parameters in rock joints based on high pressure triaxial testing
}

Buddhima Indraratna

University of Wollongong, indra@uow.edu.au

P. G. Ranjith

University of Wollongong

Follow this and additional works at: https://ro.uow.edu.au/engpapers

Part of the Engineering Commons

https://ro.uow.edu.au/engpapers/179

\section{Recommended Citation}

Indraratna, Buddhima and Ranjith, P. G.: Laboratory measurement of two-phase flow parameters in rock joints based on high pressure triaxial testing 2001.

https://ro.uow.edu.au/engpapers/179

Research Online is the open access institutional repository for the University of Wollongong. For further information contact the UOW Library: research-pubs@uow.edu.au 


\title{
Laboratory Measurement of Two-Phase Flow Parameters in Rock Joints Based on High Pressure Triaxial Testing
}

\author{
By B. Indraratna ${ }^{1}$ and P. G. Ranjith, ${ }^{2}$ Members, ASCE
}

\begin{abstract}
The accurate flow measurement of each individual phase is important in unsaturated flow through rock joints, where both air and water phases flow together. An increase in the quantity of one fluid phase decreases the relative permeability of the other phase. The relative permeability is important in numerical models to analyze the risk of ground-water inundation and uncontrollable gas flows in underground excavations in jointed rock. A new apparatus, the High Pressure Two-Phase Triaxial Apparatus (HPTPTA), has been designed for examining the strength and coefficient of permeability characteristics of fractured and intact rocks under two-phase flows. In single-phase triaxial equipment, the rock specimen is subjected to a single fluid flow (either water, oil, or gas) through the fractures. In the HPTPTA, two fluids (e.g., water + air, water + oil, and oil + air) can be forced to flow through the specimen, and the flow rates of the fluids can be measured independently. The scope of tests that can be carried out in this apparatus is wide, including the evaluation of (1) stress-strain behavior subject to internal fluid flow; (2) relative permeability of each fluid phase under different degrees of saturation; and (3) the associated volume change of the specimen. In this paper, the design concepts of the HPTPTA and the results based on the testing of fractured rock specimens are discussed. The laboratory results are compared to a simplified mathematical model developed by the writers. Based on the laboratory results, it is shown that the well-known Darcy's law can be modified for estimating the two-phase flow rates using the relative permeability concept.
\end{abstract}

\section{INTRODUCTION}

The material properties associated with the triaxial testing of soil and rock are essential in the design of various surface and underground structures. To provide meaningful data from laboratory testing, the apparatus must be capable of simulating existing in situ field conditions, including the stress-strain behavior and coefficient of permeability characteristics of rocks. For this purpose, various types of triaxial apparatus have been developed during the past four decades (Hoek and Franklin 1968; Hambly and Reik 1969; Dusseault 1981; Smart 1995; Indraratna and Haque 1999). Triaxial apparatus used for rock testing may be classified depending on (1) the capacity of the triaxial cell (i.e., high pressure or low pressure); (2) the loading system (i.e., quasi-static triaxial stress and polyaxial stress); and (3) use of single-phase or multiphase flows.

Rock joints are often unsaturated, and they usually conduct both gas $\left(\mathrm{CO}_{2}, \mathrm{CH}_{4}\right.$, and air) and water, which may also carry fine sediments (Pruess and Tsang 1990; Fourar et al. 1993). Under unsaturated flow conditions, a two-phase (or multiphase) flow analysis should be carried out. Fig. 1 illustrates whether a single or multiphase flow analysis should be carried out in a jointed rock mass. As shown in Fig. 1, single-phase flow analysis is carried out when the discontinuities carry a single fluid, whereas, when two or more fluids are present in rock fractures, multiphase flow analysis is employed to simulate the flow. For a single joint, its intrinsic permeability is given by the expression $e^{2} / 12$, where $e$ is the hydraulic aperture that can be back-calculated from the flow rate. The illustrations to the left of Fig. 1 (underneath the block and discontinuities) correspond to single-phase flow, and the illustrations to the right correspond to two-phase or multiphase flow analysis. In two-phase flow of water and gas through a rock joint, the net fluid pressure $\left(P_{w}-P_{a}\right)$, where $P_{a}$ and $P_{w}$ are air and

${ }^{1}$ Prof. of Civ. Engrg., Div. of Civ. Engrg., Univ. of Wollongong, New South Wales, 2522, Australia.

${ }^{2}$ Doctoral Candidate, Div. of Civ. Engrg., Univ. of Wollongong, New South Wales, 2522, Australia.

Note. Discussion open until November 1, 2001. To extend the closing date one month, a written request must be filed with the ASCE Manager of Journals. The manuscript for this paper was submitted for review and possible publication on August 23, 1999; revised February 21, 2001. This paper is part of the Journal of Geotechnical and Geoenvironmental Engineering, Vol. 127, No. 6, June, 2001. CASCE, ISSN 1090-0241/01/ $0006-0530-0542 / \$ 8.00+\$ .50$ per page. Paper No. 21714. water pressure, respectively, acts in addition to the ground stresses. If $P_{a}>P_{w}$, then the capillary suction $\left(P_{a}-P_{w}\right)$ acts within the joint domain to increase the apparent strength of the rock mass. While the strength often governs the load bearing capacity or failure of rock mass, the potential hazards associated with ground-water inundation and gas ingress are governed by the relative permeability of each fluid phase. The relative permeability is a nondimensional factor that would range between 0 and 1 . When the relative permeability with respect to one phase becomes unity, the relative permeability of the other phase becomes zero. For instance, if the medium is considered to be fully saturated with air, then the "relative permeability of air" is unity, and the "relative permeability of the other phases" becomes zero.

Research studies based on two-phase flow analysis have gained increasing interest in the mining and petroleum industry, because of the prudent design applications and risk assessment associated with two-phase flow through rock mass (Pruess and Tsang 1990; Rasmussen 1991; Reitsma and Kueper 1994; Fourar and Bories 1995). Rock fractures will exhibit different flow patterns (complex or mixed) depending on the magnitude of fluid pressures within joints, joint geometry, and the external stress. Within a typical rock joint, any of the possible flow regimes shown in Fig. 2 may be encountered, which are classified according to the continuity or discontinuity of either the water or the air phase. From the limited literature available, it is clear that there are no reliable procedures still available to accurately estimate the flow rates of each fluid phase, reflecting the vast research scope yet to be achieved in hydromechanics of jointed rock.

The work presented herein is an attempt to introduce a new direction in the laboratory measurement of water and air flow through a fractured rock specimen and supported by theoretical formulations based on a simplified (stratified) flow model. The salient features of the High Pressure, Two-Phase Triaxial Apparatus (HPTPTA) developed by the writers are also discussed.

\section{SIMPLIFIED THEORY FOR TWO-PHASE, STRATIFIED FLOW}

In general, fluid flow through a rock mass is the accumulated effect of flow through the porous rock matrix and the flow through the joint network. In hard rocks (low porosity), 


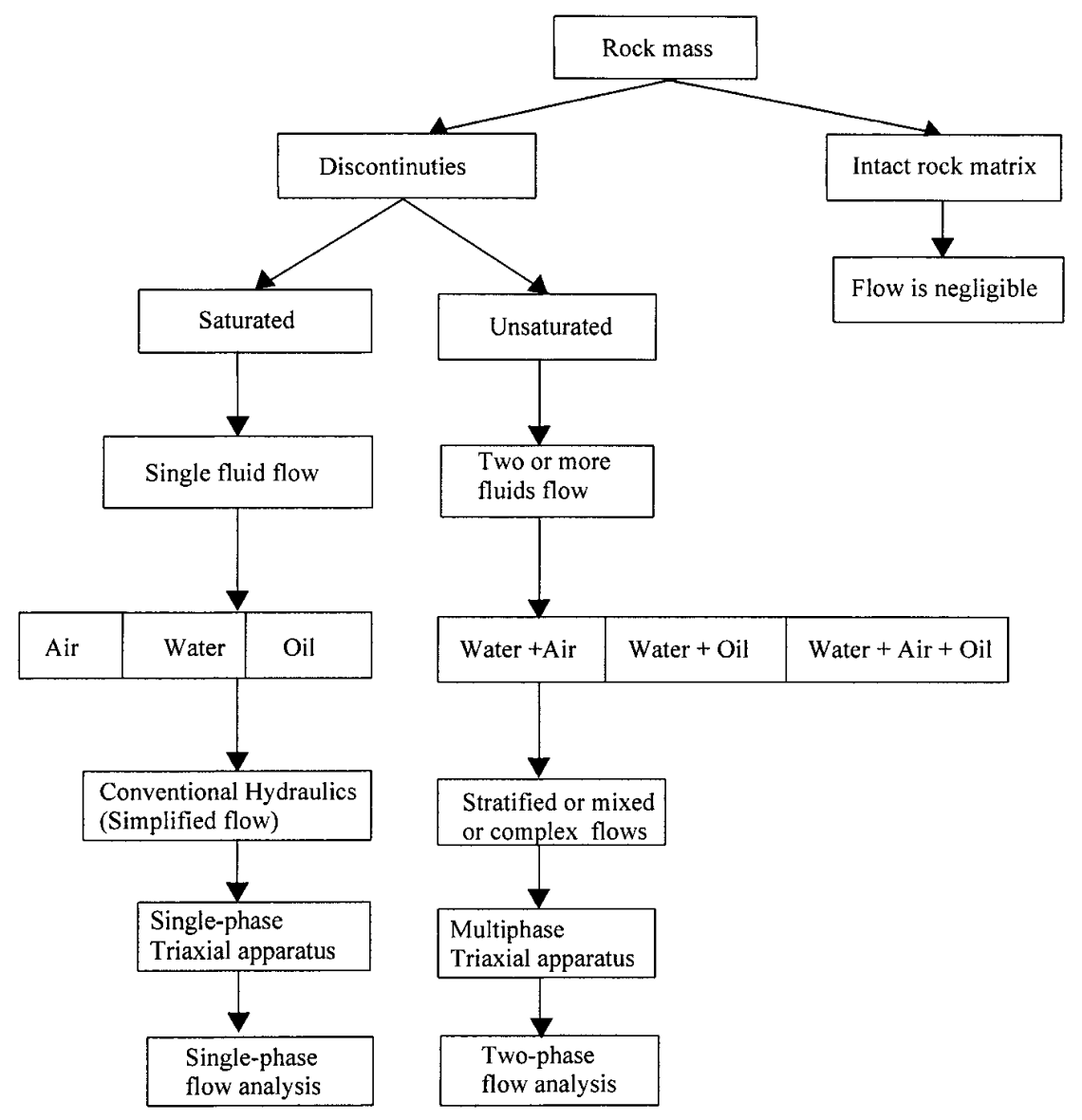

FIG. 1. State of Fluid Flow through Rock Joints

the fluid flow is dictated through the passage of discontinuities. In the past, various research studies have been conducted to analyze single fluid flow either through a single joint or through a network of fractures (Neuzil and Tracy 1981; Tsang and Witherspoon 1981; Amadei and Illangasekare 1994). In single-phase flow analysis, based on a smooth joint with parallel walls, flow quantity can be estimated using Darcy's cubic formula, as given by the following equation:

$$
Q=-\frac{e^{3} w}{12 \mu}\left[\frac{\partial P}{\partial x}+\rho g \frac{\partial z}{\partial x}\right]
$$

where $Q=$ flow rate $\left(\mathrm{M}^{3} \mathrm{~T}^{-1}\right) ; e=$ joint aperture $(\mathrm{L}) ; P=$ fluid pressure $\left(\mathrm{M} \mathrm{L}^{-1} \mathrm{~T}^{-2}\right) ; \mu=$ dynamic viscosity of the fluid $(\mathrm{M}$ $\left.\mathrm{L}^{-1} \mathrm{~T}^{-1}\right) ; \rho=$ density of the fluid $\left(\mathrm{M} \mathrm{L}^{-3}\right) ; g=$ acceleration due to gravity $\left(\mathrm{L} \mathrm{T}^{-2}\right) ; x=$ direction of flow $(\mathrm{L}) ; z=$ vertical direction (L); and $w=$ width of the fracture (L).

The hydraulic aperture (e) can be derived from (1) as follows:

$$
e=\left[\frac{12 Q \mu}{w\left(\frac{\partial P}{\partial x}+\rho g \frac{\partial z}{\partial x}\right)}\right]^{1 / 3}
$$

Although the cubic law overestimates the flow rate because it does not take into account the effect of joint roughness, it is still widely used in practice because of its simplicity and the ease of inclusion in numerical modeling. The validity of (1) for two-phase flow can be questionable, especially when the joint roughness is significantly high. The flow pattern within a joint may adopt either mixed or stratified conditions (Fig. 2), depending on the fluid flow velocity, joint roughness, and the degree of saturation (with respect to water). Assuming stratified flow, the equivalent heights of water phase and air phase relative to a given coordinate system can be determined; for example, the $x$-axis can be chosen along the bottom wall of the joint, and the $y$-axis taken perpendicular to the joint. The complete derivations of the mathematical model are given elsewhere; hence, only the governing equations are presented here.

The heights of water phase, $h_{w}(t)$, and the air phase, $h_{a}(t)$, are represented by

$$
\begin{gathered}
h_{w}(t)=F_{I}(x, y)_{0}-F_{B}(x, y)_{0}-\xi_{w c} \\
h_{a}(t)=F_{T}(x, y)_{0}-F_{I}(x, y)_{0}-\left(\xi_{a c}+\xi_{a d}+\delta_{n}-\xi_{w c}\right)
\end{gathered}
$$

where $F_{T}(x, y)_{0}$ and $F_{B}(x, y)_{0}=$ initial surface profiles of top and bottom joint walls, respectively; $F_{I}(x, y)_{0}=$ interface profile between two fluids; $\xi_{w c}=$ level change due to the compressibility of water; $\xi_{a c}=$ level change due to the compressibility of air; $\xi_{a d}=$ level change due to the solubility of air in water; and $\delta_{n}=$ elastic deformation of the joint wall.

For insignificant capillary pressure, the writers have derived $F_{I}(x, y)_{0}$ using the principles of mass and momentum conservation for two-phase flow in a given rock joint, as follows:

$$
\begin{aligned}
& F_{I}(x, y)_{0} \\
& \quad=\frac{\tau_{j a} F_{B}\left(x, y, \Delta_{B}\right)+\tau_{j w} F_{T}\left(x, y, \Delta_{T}\right)-\tau_{w a}\left[F_{T}\left(x, y, \Delta_{T}\right)-F_{B}\left(x, y, \Delta_{B}\right)\right]}{\tau_{j a}+\tau_{j w}}
\end{aligned}
$$

where

$$
\begin{gathered}
F_{T}\left(x, y, \Delta_{T}\right)=\left[F_{T}(x, y)_{0}-\xi_{a c}+\xi_{a d}+\delta_{n}-\xi_{w c}\right] \\
F_{B}\left(x, y, \Delta_{B}\right)=F_{B}(x, y)_{0}+\xi_{w c}
\end{gathered}
$$


(a) Possible stratified flow patterns (Both phases continuous)

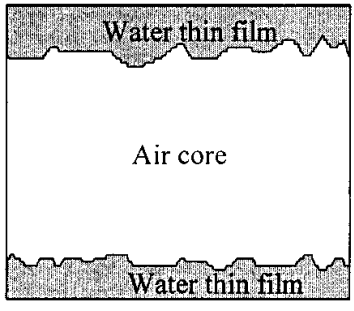

(i) Air core is covered by thin film of water

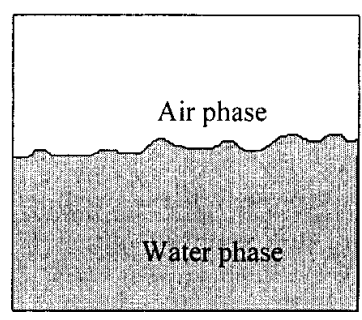

(ii) Stratified wavy flow

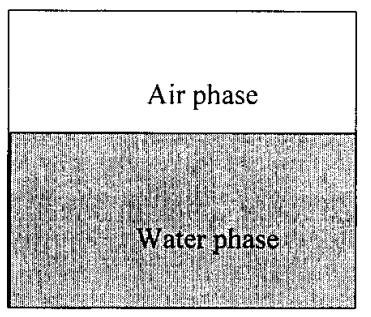

(iii) Simplified stratified flow (assumed in authors' model)

(b) Mixed flows (One phase is continuous)

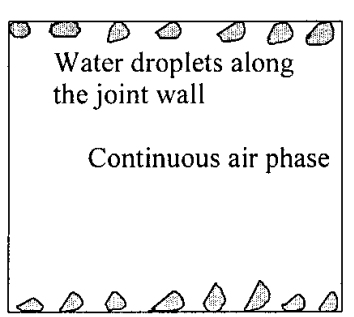

(i) Water droplets in continuous air phase

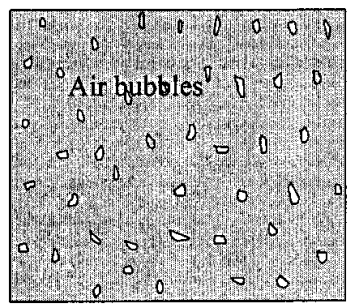

(iv) Bubble flow

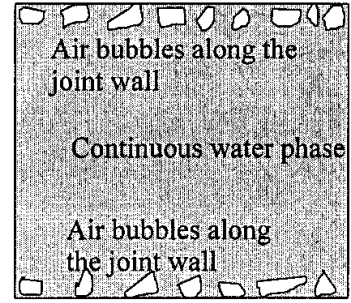

(ii) Air bubbles in continuous water phase

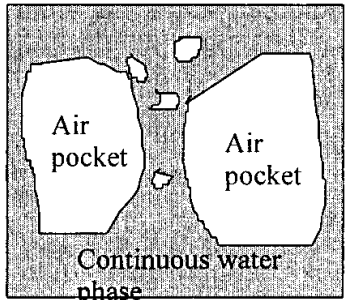

(iii) Air pockets in continuous water phase

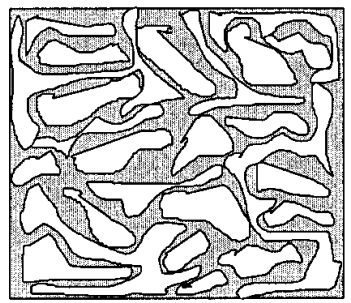

(v) Complex flow

FIG. 2. Possible Flow Patterns in Typical Rock Joint

In (5), $\tau_{j w}$ and $\tau_{j a}=$ shear stresses acting on the joint wall due to the water and air phases, respectively. They are determined by the expression, $f_{i} \rho_{i} \mathbf{V}_{i}^{2} / 2$, where $f_{i}=$ friction factor between joint wall and fluid phase, $\rho_{i}=$ density of the fluid phase, and $\mathrm{V}_{i}=$ velocity of the fluid phase. The subscript $i$ assumes $w$ for water or $a$ for air. The variable $\tau_{w a}=$ shear stress acting on the water-air interface.

For two-phase flow in a smooth joint with parallel walls, phase flux of wetting (water phase) and nonwetting (air phase) can be expressed as follows:

For wetting-phase (water phase), the phase flux is given by

$$
q_{W}=-\frac{k k_{r W}}{\mu_{W}}\left[\frac{\partial P_{W}}{\partial x}+\rho_{W} g \frac{\partial z}{\partial x}\right]
$$

For nonwetting phase (air phase), the phase flux is given by

$$
q_{N}=-\frac{k k_{r N}}{\mu_{N}}\left[\frac{\partial P_{N}}{\partial x}+\rho_{N} g \frac{\partial z}{\partial x}\right]
$$

where $k=$ intrinsic permeability $\left(\mathrm{L}^{2}\right) ; k_{r}=$ relative permeability (nondimensional); $q=$ flux $\left(\mathrm{L} \mathrm{T}^{-1}\right)$; and subscripts $W$ and $N$ represent wetting and nonwetting phases. Other variables have been defined under (1).

Eq. $(6 b)$ can be coupled with the capillary pressure (i.e., $P_{C}$ $\left.=P_{N}-P_{W}\right)$ as given below

$$
q_{N}=-\frac{k k_{r N}}{\mu_{N}}\left[\frac{\partial\left(P_{C}+P_{W}\right)}{\partial x}+\rho_{N} g \frac{\partial z}{\partial x}\right]
$$

The following equations represent the relative permeability for wetting (water phase) and nonwetting phase (air phase), respectively:

For the water phase (wetting phase)

$$
k_{r W}=-\frac{q_{W} \mu_{W}}{k\left(\frac{\partial P}{\partial x}+\rho_{W} g \frac{\partial z}{\partial x}\right)}
$$

For the air phase (nonwetting phase)

$$
k_{r N}=-\frac{q_{N} \mu_{N}}{k\left(\frac{\partial P}{\partial x}+\rho_{N} g \frac{\partial z}{\partial x}\right)}
$$

Flow rate $(Q)$ is given by $Q=q e w$, where $q$ is the phase flux, $e$ is the joint aperture, and $w$ is the width of the fracture.

In the laboratory, once the values of $Q_{a}$ (i.e., $Q_{N}$ ) and $Q_{w}$ (i.e., $Q_{W}$ ) are measured, the relative permeability of each phase $k_{r}$ can be easily determined by (7). In the mathematical model, using (3) and (4), the phase heights $h_{a}(t)$ and $h_{w}(t)$ are calculated first in order to estimate $q_{a}$ and $q_{w}$ [(6)], which are then substituted in (7) to determine $k_{r}$ of wetting and nonwetting phases.

\section{TWO-PHASE TRIAXIAL APPARATUS FOR UNSATURATED MEDIA}

Various laboratory methods have been used to investigate the permeability characteristics under steady-state and un- 
steady-state conditions (Klute 1965; Barden and Pavlakis 1971; Fredlund and Rahardjo 1993; Huang et al. 1998). Reitsma and Kueper (1994) investigated the measurement of the capillary pressure-saturation relationship in rough rock fractures under different normal stresses. According to the method described by Klute (1965), water was supplied to the specimen from an overhead water tank, and the water pressure was measured by two tensiometers. The constant air pressure was measured using a manometer. The tests were carried out for different suction pressures $\left(P_{a}-P_{w}\right)$, where $P_{a}$ is air pressure, and $P_{w}$ is the water pressure. In Klute's apparatus, the change of permeability with respect to the change of axial stress has not been addressed. Hamilton et al. (1981) studied the conductivity of partially saturated soil for different suction pressures. They found that the water permeability decreases with the increase in the degree of air saturation in the soil. Barden and Pavlakis (1971) reported similar test results of air and water conductivity on a boulder clay. Such laboratory tests conducted on unsaturated soil and rocks have influenced, to a significant extent, the subsequent development of two-phase triaxial equipment for jointed rocks.

Although much experimentation has been carried out to understand the complete two-phase (air-water) flow behavior in the field of chemical and mechanical engineering, the proper

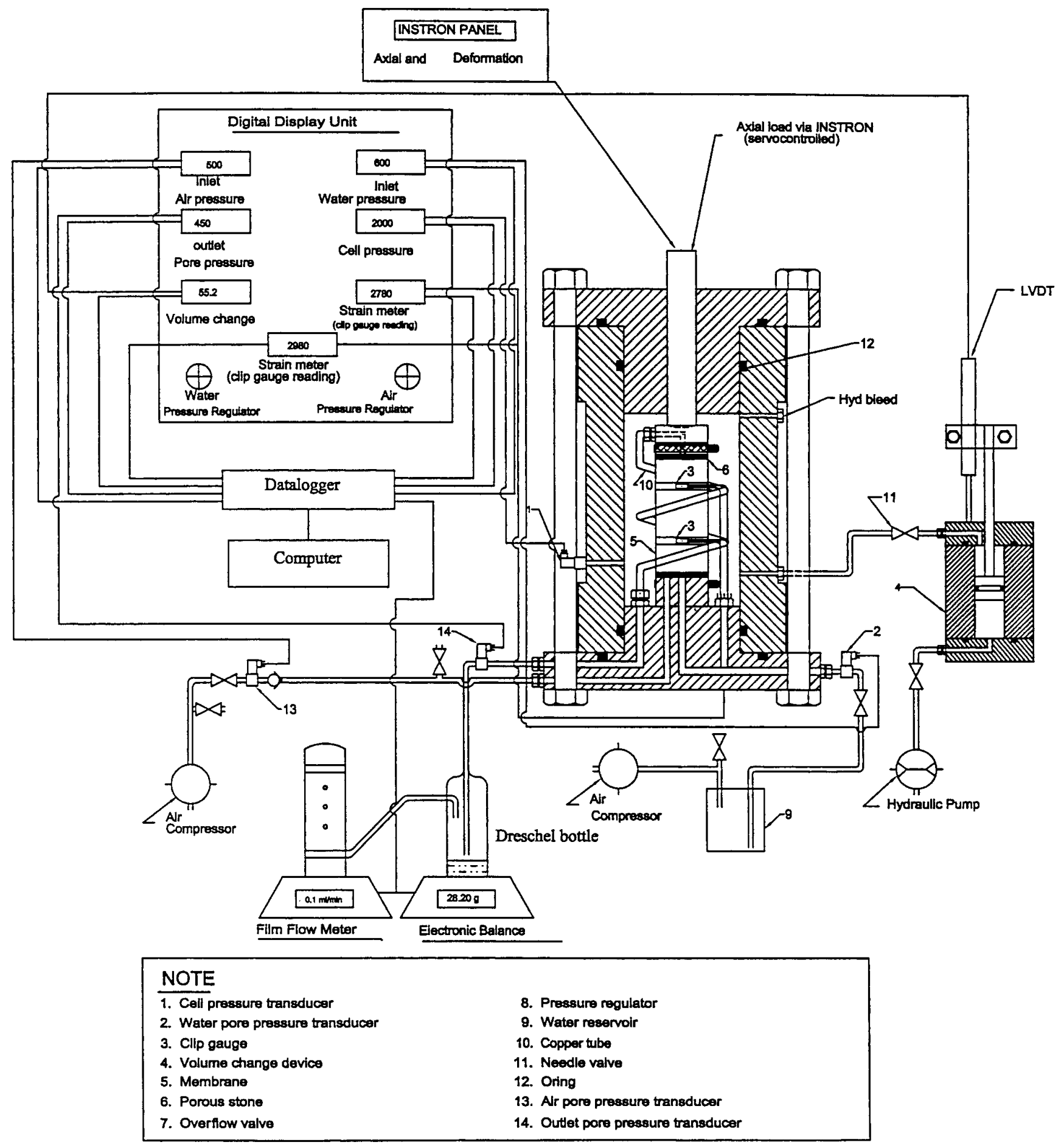

FIG. 3. Schematic Diagram of HPTPTA 
understanding of two-phase flow behavior in jointed rocks still remains at infancy because of the complexity of geological variabilities. A number of available triaxial facilities can measure either the pore-water pressure or pore-air pressure within a fractured rock, but they are still incapable of measuring the relative permeability (air or water) of a fractured specimen. It is the relative permeability data that are most useful in the numerical analysis of flow through jointed rock mass. To study the two-phase flow behavior through fractured rock specimens, the writers designed a new equipment, namely, the HPTPTA. This is a significant modification of the single-phase triaxial apparatus designed previously by Indraratna and Haque (1999) at the University of Wollongong.

\section{Salient Features of HPTPTA}

The following section describes the salient features of the above two-phase triaxial apparatus, which can measure the relative permeability of each fluid phase, in addition to the stressstrain characteristics of rock specimens subjected to axial and confining pressure. The HPTPTA is designed to measure the following:

- Single-phase permeability for saturated specimen

- Two-phase, relative permeability for unsaturated flows

- Lateral deformation of the specimen at different locations (using clip gauges attached to the membrane)

- Volume change of the specimen through a volume change device

- Inlet fluid pressures of water and air separately using pressure transducers

- Discharge fluid pressure (water + air) using a pressure transducer (The water pressure was measured at the outlet, as the air phase comes to equilibrium with the atmospheric pressure during drained flow under triaxial test conditions.)

- Axial deformation using a servocontrolled Instron machine

A schematic diagram of the HPTPTA is illustrated in Fig. 3 . The cell is made from high yield steel having a $0.1-\mathrm{m}$ in- ternal diameter and a $0.12-\mathrm{m}$ height. The modified cell can accommodate a range of specimens from 0.045 to $0.06 \mathrm{~m}$ in diameter. In this equipment, water and air phases are transported by two separate lines to the bottom end of the specimen. To prevent effects of air flow on water flow, the two separate lines that carry water and air are integrated with several on/off valves and check valves. These valves attached to the bottom plate ensure that there is no back flow of one phase through the line of the other phase. To monitor the pressure of each phase, a pressure transducer is attached to each line. Under drained flow in triaxial test conditions, the capillary pressure at the outlet was set to equal the inlet capillary pressure during the tests. In HPTPTA, the lateral deformation of the specimen is measured using the circumferential clip gauges, which are mounted onto the specimen membrane.

Before using any flowmeters to monitor the air and water flow rates, the air-water mixture from the specimen has to be separated, because the commercially available flowmeters are only designed for measuring single-phase flow at a time. In the HPTPTA, the air-water mixture from the triaxial specimen is allowed to flow through a Dreschel bottle. The air phase separates out from the Dreschel bottle and passes into the film flowmeter, while the water remains in the Dreschel bottle that is kept on a sensitive electronic balance (Fig. 3). For air flow measurement, the electronic film flowmeter (STEC 1998) is most appropriate, which provides automatic flow measurement with high accuracy. Such electronic flowmeters are also equipped with a high precision sensor to incorporate any atmospheric pressure changes. This instrument basically consists of two parts: (1) measuring unit; and (2) measuring tubes, for typical flow rates of $0.2 \mathrm{~mL} / \mathrm{min}$ to $10 \mathrm{~L} / \mathrm{min}$. The water flow measurement is recorded by the electronic weighing balance, which also provides good accuracy within $1 \%$ error. A datalogger is employed for acquisition of measurements from all transducers, flow measurement devices, strain meters, and LVDTs.

\section{LABORATORY TEST PROCEDURE}

A series of tests were conducted on fractured granite rocks using the HPTPTA, and the test procedure is briefly explained

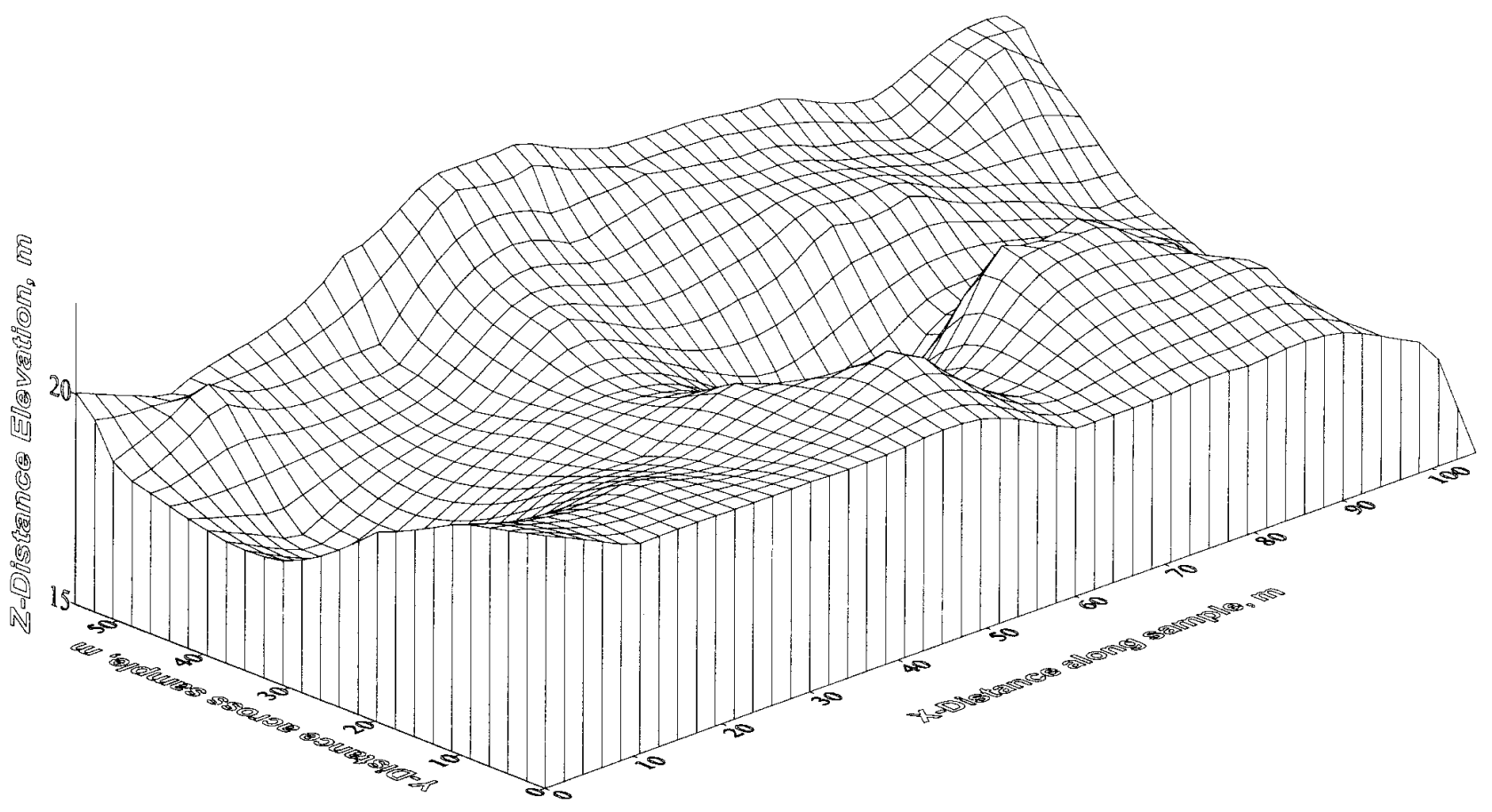

FIG. 4. Typical Joint Surface Profile 
below. The tested specimens were characterized by a single fracture along the specimen length, which was induced in the laboratory. The width of the fracture was almost equal to the specimen diameter. Fig. 4 represents the joint surface profile of a typical specimen, mapped using the digital profilometer After smoothening both ends of the rock specimen, it is then covered by a polyurethane membrane and subsequently placed on the bottom seat of the triaxial cell. The orientation of the fracture was near vertical, and the specimen was tested vertically in the direction of axial stress, $\sigma_{1}$. To measure the lateral deformation of the rock specimen, two specially designed clip gauges are mounted at $1 / 3$ length of the specimen on the mem-

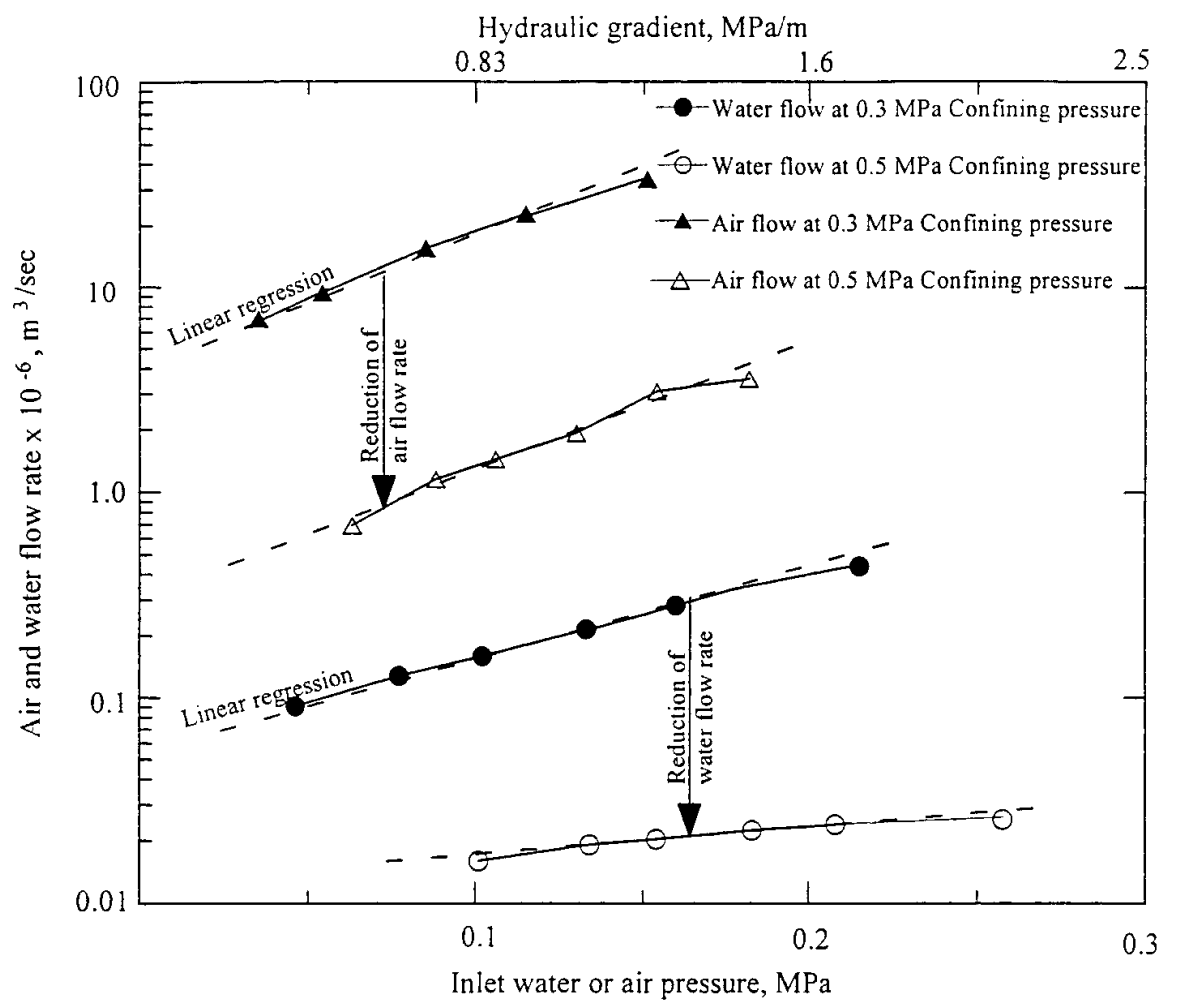

FIG. 5. Effect of Increasing Confining Pressure and Inlet Fluid Pressure: Single-Phase Air and Water Flow Rates

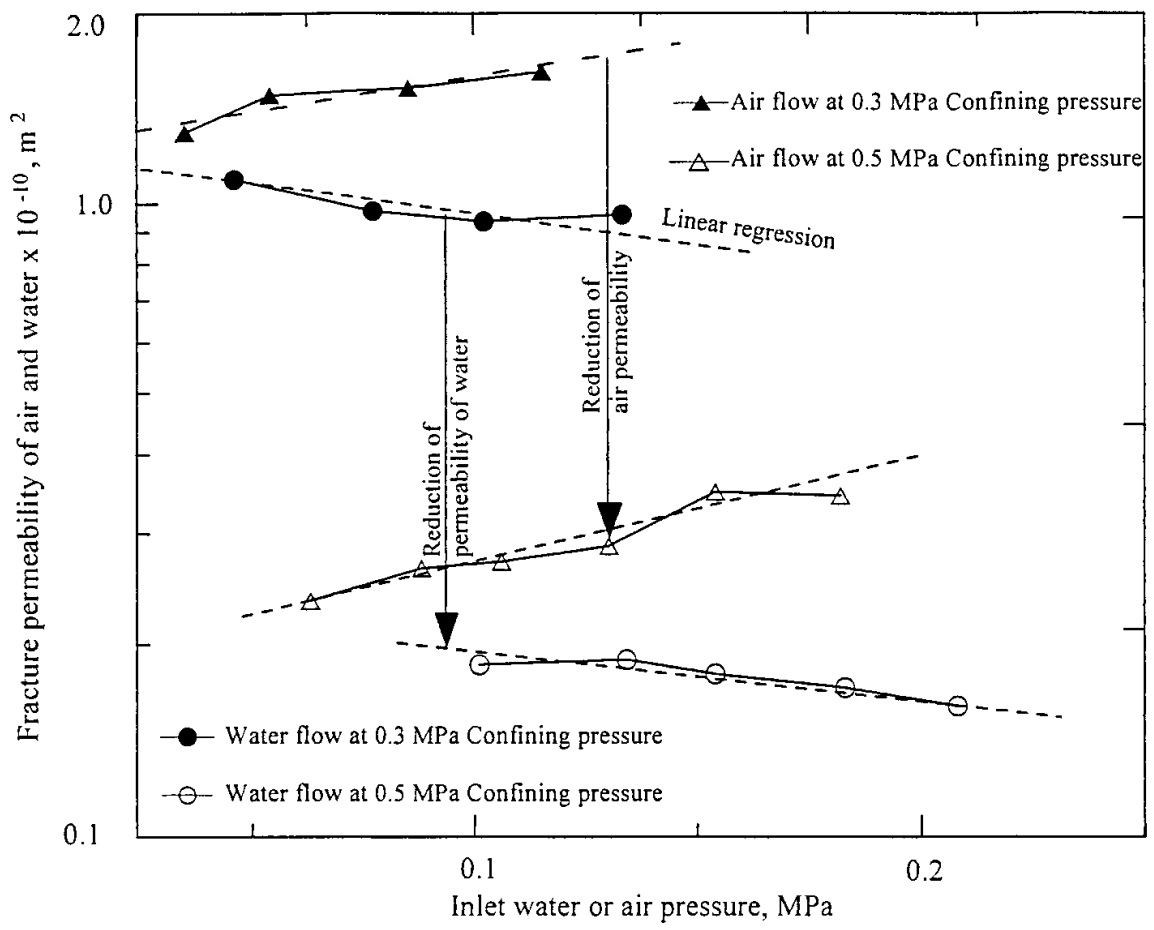

FIG. 6. Comparison of Single-Phase Water and Air Permeability at Different Confining Pressure 
brane. Using two horseshoe clamps, the membrane is tightened to the top and bottom seating so that no fluid flow through the membrane and the specimen takes place. The spiral tube (Fig. 3 ) is fixed to carry fluid flow from the specimen to the outlet. Oil is filled inside the cell from the top to the air bleeding hole, and then the top and bottom bases are tightened by six bolts. To ensure no trapped air is inside the cell, oil is further pumped into the cell using a hydraulic jack. The specimen is first saturated with one fluid phase, and then the second phase is forced through the specimen. Both capillary pressures at the inflow and outflow were fixed over time, and they also were set to be equal during the test using the fine adjustment valves fitted to the triaxial unit. The readings of the inlet air pressure transducer, inlet water pressure transducer, outlet pressure transducer of both air and water, cell pressure transducer, volume change device, and axial and lateral deformations are monitored continuously and displayed digitally on the instrumentation display unit prior to recording by the datalogger. Once the water and air mixture passes through the Dreschel bottle, air flow rates and water flow quantities are recorded by the film flowmeter and electronic weighing scale, respectively.

\section{TEST RESULTS AND DISCUSSION}

Test results discussed in this section are based on steadystate flow measurements. For a given confining pressure and axial stress, Fig. 5 shows that single-phase air and water flow rates (on log axis) vary approximately linearly with inlet fluid pressure. It is not feasible to plot both flow rates on the same arithmetic scale axes, as the water flow rates are much smaller than the air flow rates. During the single-phase flow analysis, there was no second fluid phase present. For each set of data, the pressure gradient can be determined by the difference between the inlet and the outlet pressures divided by the length of the flow path. In drained flow states under triaxial conditions, the outlet pressure comes to equilibrium with the atmospheric pressure; therefore, only the inlet fluid pressure is included in Fig. 5. As the gravity effects are small compared to the inlet pressure term, the total pressure gradient can be approximated by the inlet pressure gradient. With the increase of inlet fluid pressure, the flow rates also increase as expected. At elevated confining pressure $(0.5 \mathrm{MPa})$, both air and water flow rates diminish by more than $80 \%$ from the corresponding flow rates at 0.3-MPa cell pressure. This can be attributed to the closure of joint apertures. As discussed in the past by various researchers (Witherspoon et al. 1980; Gale et al. 1985), Darcy's law can still be applied to natural rock fractures at relatively low confining pressures.

Single-phase intrinsic permeability $\left(k=e^{2} / 12\right)$ (Priest 1991; Lee and Farmer 1993) against inlet fluid pressure is plotted in Fig. 6. Intrinsic permeability of air increases with the increasing inlet air pressure, but the intrinsic permeability based on water decreases with the increasing inlet water pressure, although the water flow rate itself increases slightly (Fig. 5). The decrease in intrinsic permeability based on water can be explained as follows. The hydraulic aperture $(e)$ is back-calculated using (2). The change in aperture is not just a function of increased $\partial p / \partial x$ (inlet pressure gradient), but it is also a

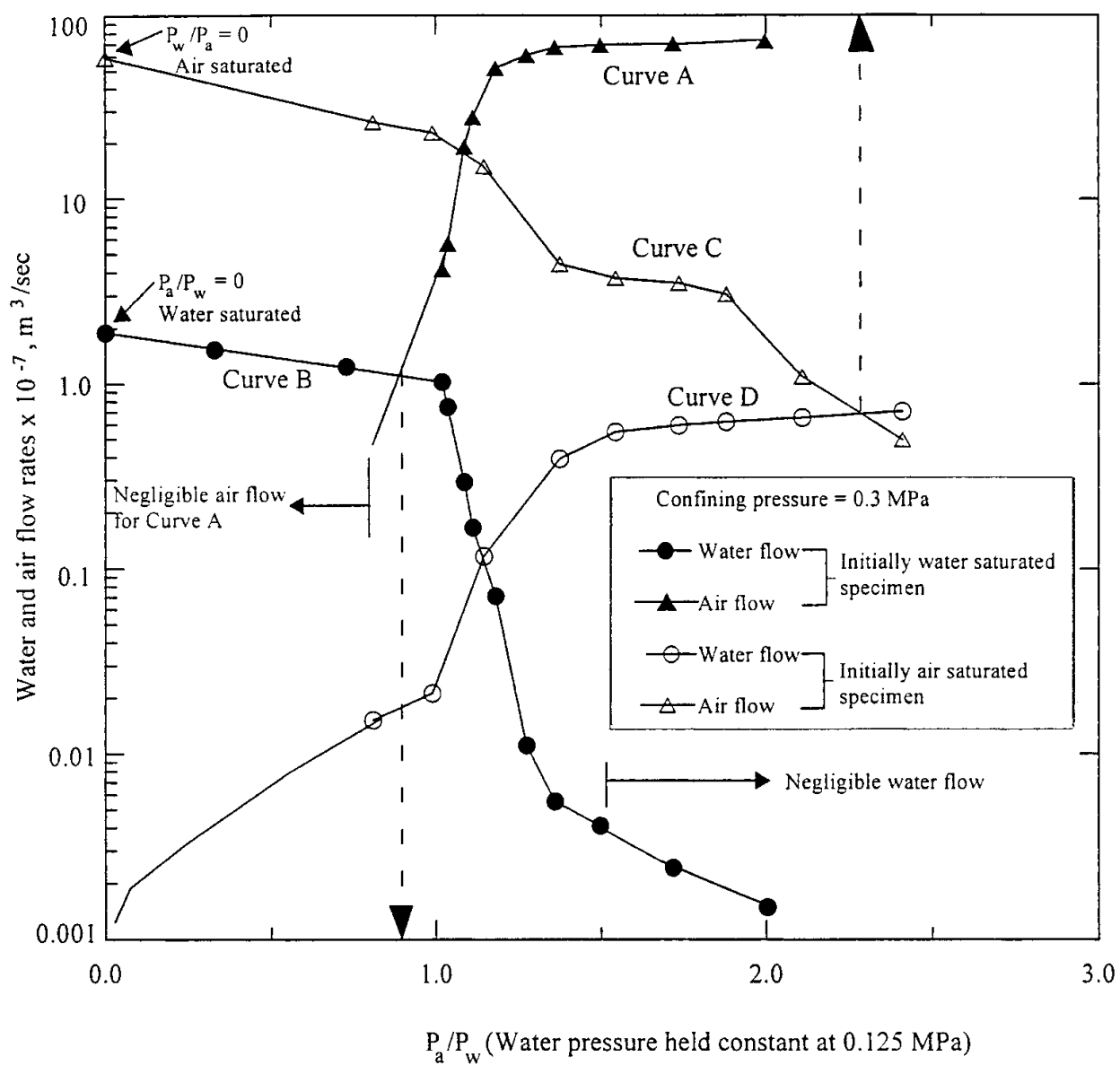

FIG. 7. Two-Phase Flow through Initially Water- and Air-Saturated Specimens 
function of the current confining pressure for both single- and two-phase flows. However, the confining pressure term is not directly included in the cubic flow expression. Even if the normal stress acting on the joint is large enough to prevent dilation (i.e., $e$ remains relatively constant), an increase in $\partial p /$ $\partial x$ can still increase the flow rate, $Q$. According to (2), any increase in the term $\partial p / \partial x$ should be accompanied by a more than proportionate increase in $Q$, to reflect an increased value of $e$. For situations where the increase in $Q$ is less than proportionate to the increase in $\partial p / \partial x$, the value of $e$ will be smaller, resulting in a reduced permeability $\left(e^{2} / 12\right)$.

At a given confining pressure and axial stress, the two-phase flow rate against the inlet fluid pressure ratios is plotted in Fig. 7, where $P_{a}$ is the inlet air pressure, and $P_{w}$ is the inlet water

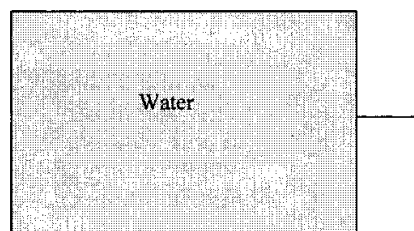

Fully saturated water flow

$\mathrm{P}_{\mathrm{w}}=$ water pressure

$P_{\mathrm{a}}=$ no air pressure

(a)

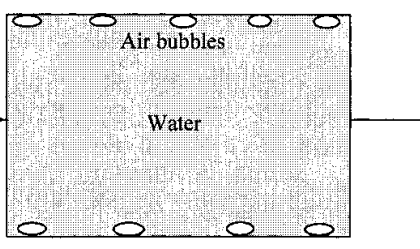

Two-phase flow

$$
\mathrm{P}_{\mathrm{w}} \cong \mathrm{P}_{\mathrm{a}}
$$

(b)

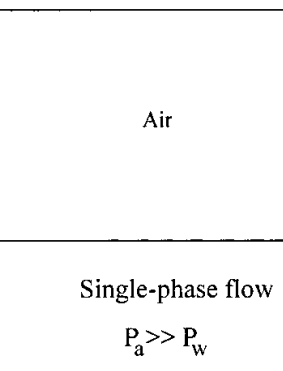

(e)

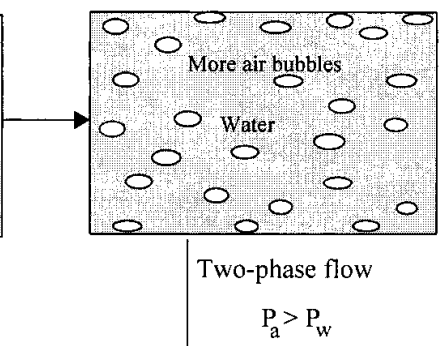

(c)

FIG. 8. Possible Flow Mechanisms within Joint

$\mathrm{P}_{\mathrm{w}} / \mathrm{P}_{\mathrm{a}}$ (Air pressure held constant at $0.125 \mathrm{MPa}$ )

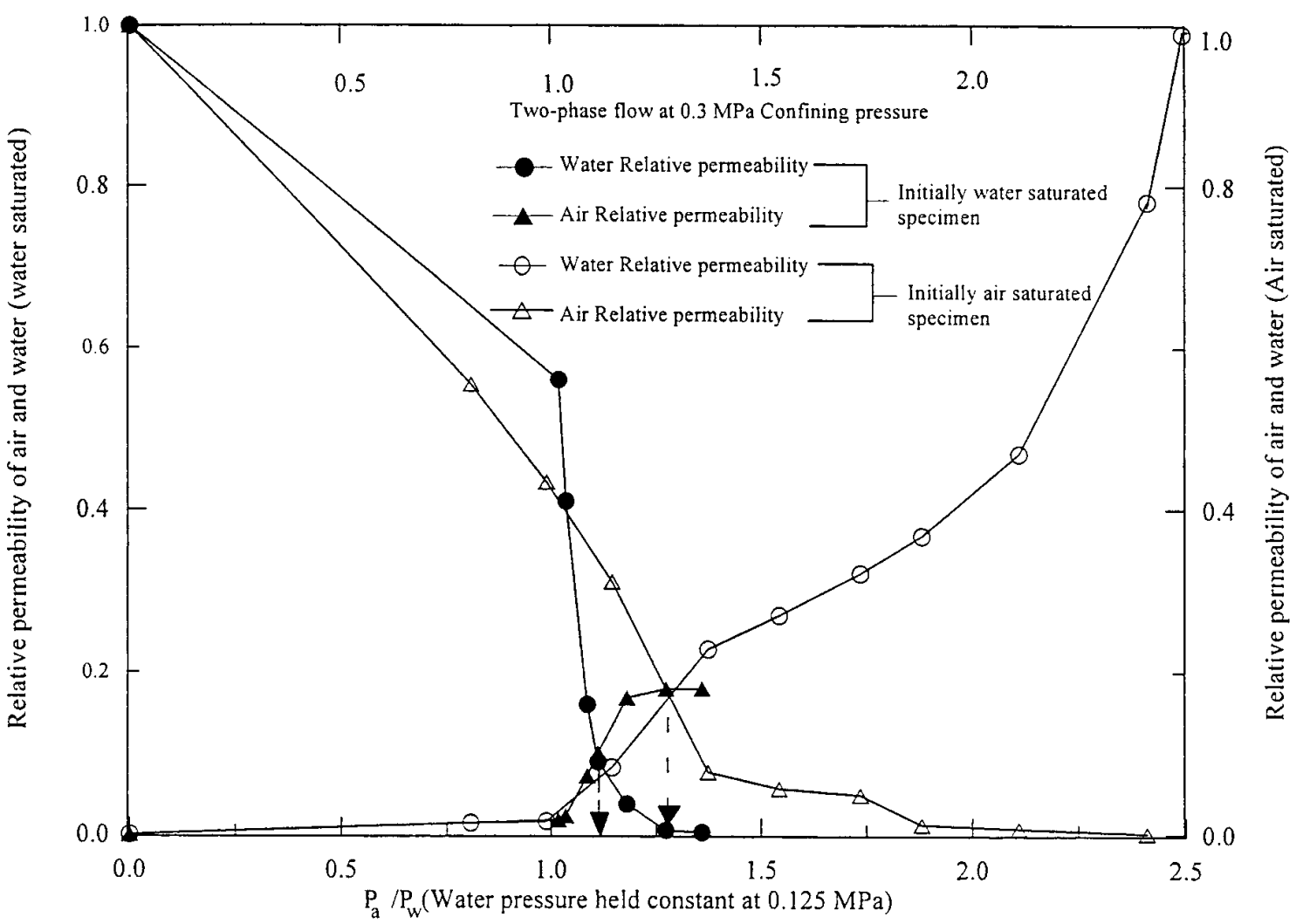

FIG. 9. Relative Permeability of Air and Water for Initially Water-Saturated and Air-Saturated Specimens 
pressure. The flow rates (vertical axis) are plotted on a $\log$ scale, in order to improve the clarity of the relatively small water flow rates in relation to the air flow rates. The pressure ratio $P_{a} / P_{w}$ is zero, when the specimen is initially saturated with water, i.e., starting point on Curve B. Similarly, the ratio $P_{w} / P_{a}$ becomes zero, when the specimen is initially saturated with air, i.e., starting point on Curve C. For a given combination of confining pressure, axial stress, and inlet water pressure, when the inlet air pressure is increased for the initially water saturated specimen, the water flow rate decreases (Curve B). The air flow becomes significant and begins to increase after a $P_{a} / P_{w}$ ratio of 0.9 (Curve A). Below this ratio, the water flow was negligible $\left(<1 \times 10^{-10} \mathrm{~m}^{3} / \mathrm{s}\right)$. It is of interest to note that when the inlet pressure ratio approaches 1 , the water and air flow rates tend to become equal. At this point, the reduced water flow rate is approximately half of the initial water flow rate when $P_{a} / P_{w}=0$. Beyond an inlet pressure ratio of unity, the water flow rate decreases rapidly, and with further increase
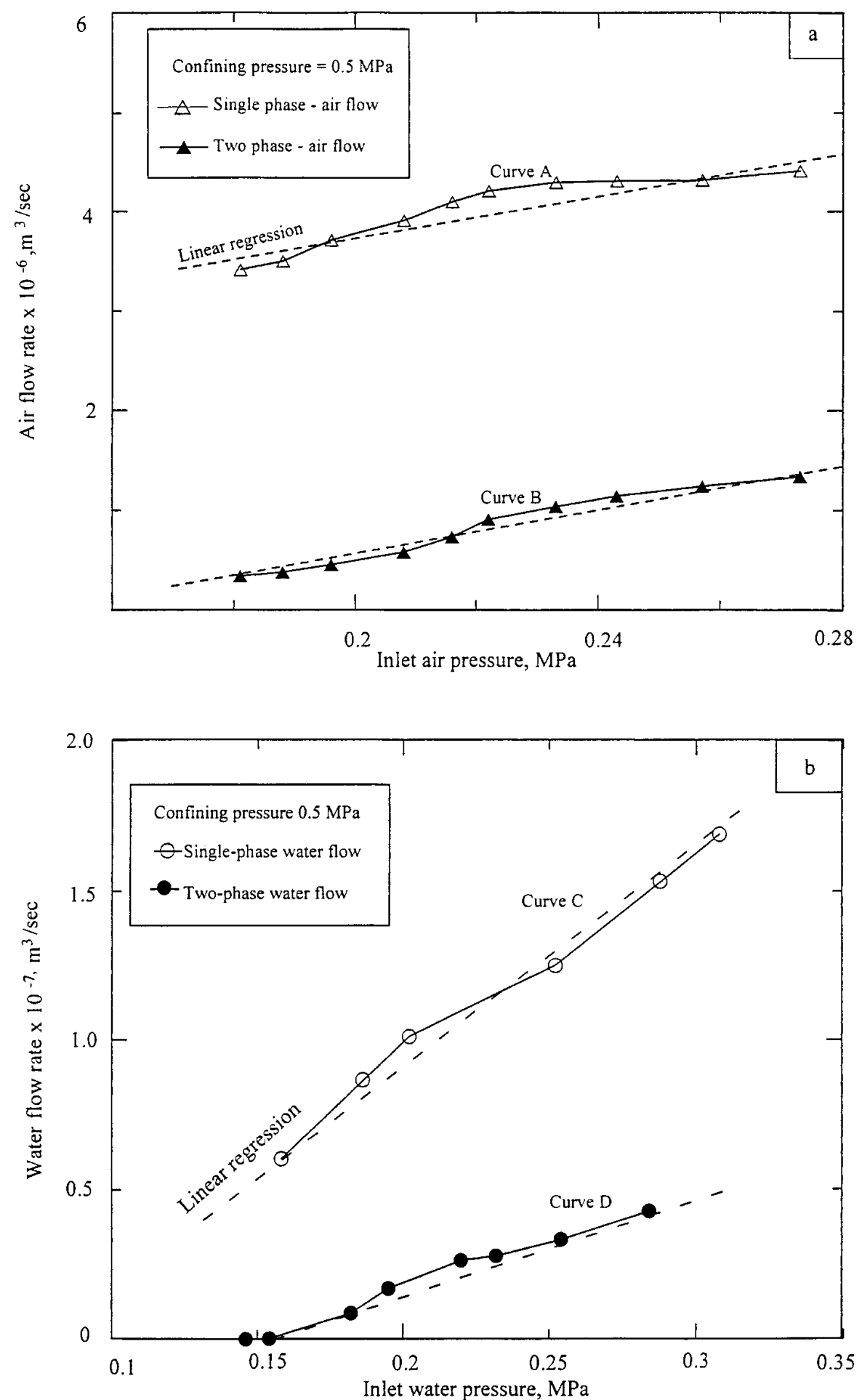

FIG. 10. Comparison of Single-Phase and Two-Phase Flow Rates: (a) Air Flow Rates $P$ Held Constant at 0.2 MPa; (b) Water Flow Rates $P$ Held Constant at $0.2 \mathrm{MPa}$ 
in air pressure, the water phase is replaced by air, resulting in insignificant water flow through the specimen $(<1 \%$ of initial water flow) when $P_{a} / P_{w}$ exceeds 1.5 . For air-saturated specimens, two-phase flow rates against inlet pressure ratio are represented by Curves C and D in Fig. 7. Air and water flow rates become equal when the inlet water pressure is approximately 2.3 times the inlet air pressure. At this point, the two-phase flow rate is approximately equal to $2 \%$ of the initial (singlephase) air flow rate at $P_{w} / P_{a}=0$.

One of the possible flow mechanisms that can occur within

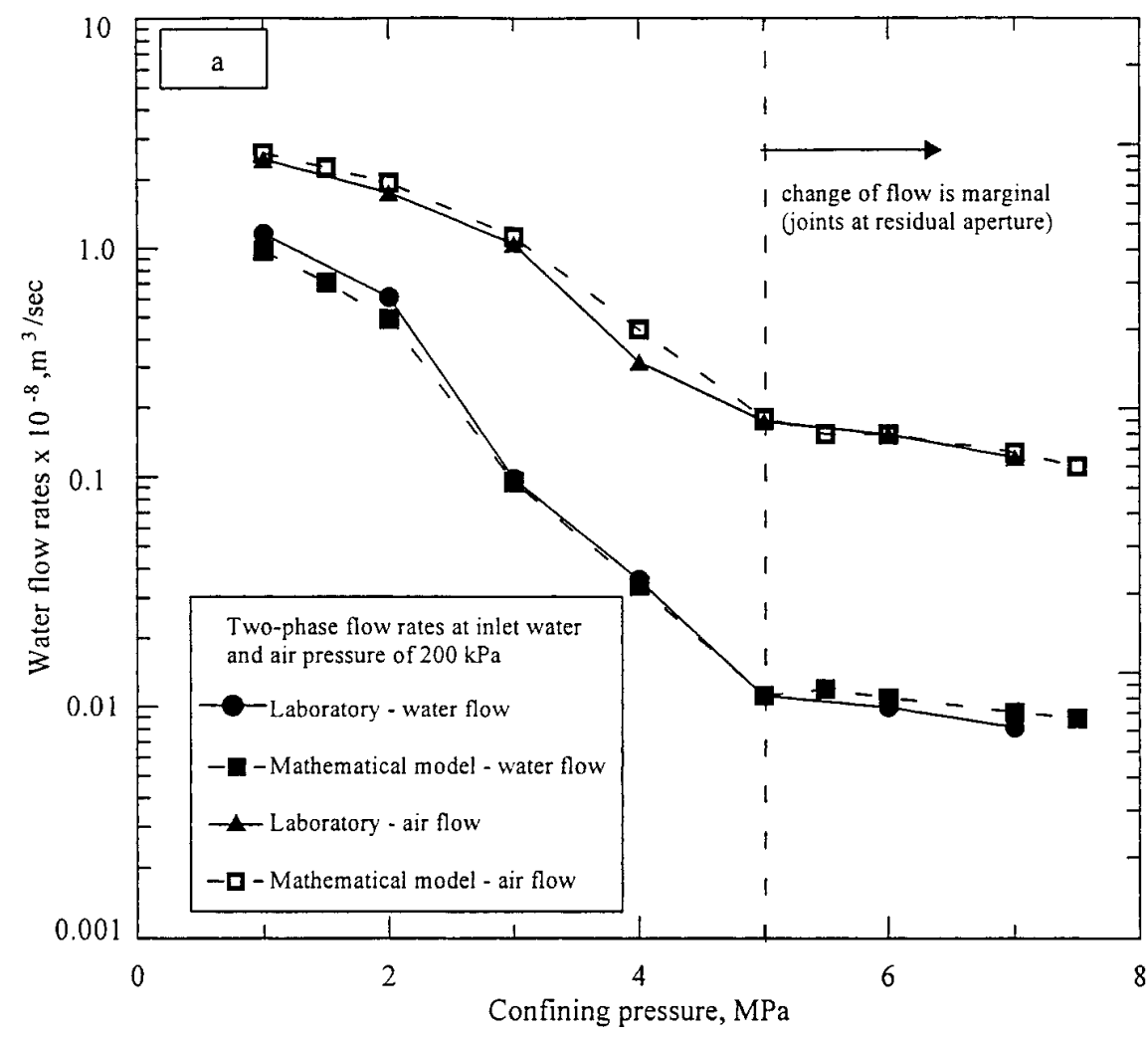

10

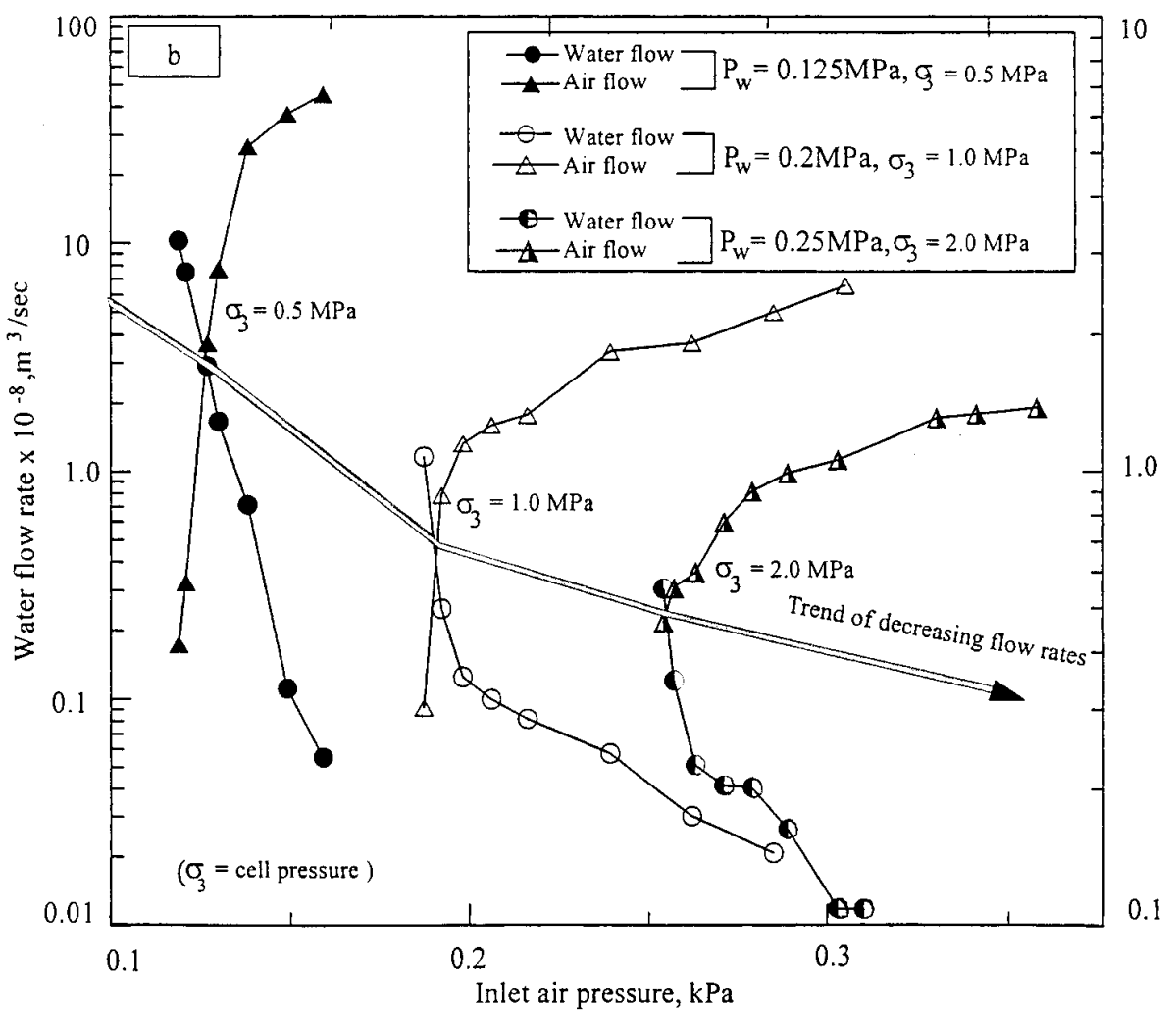

FIG. 11. Effect of Confining Pressure on Two-Phase Flow Rates: (a) Inlet Water and Air Pressure Held Constant at 0.2 MPa; (b) Inlet Water and Air Pressure Held Constant at $0.125,0.20$, and $0.25 \mathrm{MPa}$ 
a joint is explained below. When the joint is fully saturated with water, it is assumed that the joint has no air [Fig. 8(a)], and with the subsequent injection of the air phase will result in the development of a string of tiny air bubbles within the joint [Fig. 8(b)]. Further increase in air pressure will result in more air bubbles to produce "bubble flow" in the joint [Fig. 8(c)]. For elevated capillary pressures $\left(P_{a} \gg P_{w}\right)$, a complex flow pattern may develop within the joint [Fig. 8(d)], and, ultimately, single-phase air flow may result once the water phase is totally replaced by air [Fig. 8(e)].

Fig. 9 shows the relative permeability [using (7)] against inlet fluid pressure ratios. The relative permeability of a given fractured rock specimen to the air phase and to the water phase is different because one fluid is wetting and the other is nonwetting. Along main drainage, for example, the nonwetting phase enters progressively smaller aperture regions of the fractures. This causes a very rapid decrease in wetting phase relative permeability alongside a gradual increase in the nonwetting phase relative permeability. The effects of density and viscosity of fluid are insignificant to the relative permeability values. The relative permeability coefficients for both water and air plotted in Fig. 9 are calculated using (7). As demonstrated in Fig. 9, when the ratio of $P_{a} / P_{w}$ increases, the relative permeability of air increases, while the relative permeability of water decreases. The opposite trend occurs when the $P_{w} / P_{a}$ ratio is increased. For a given confining pressure and axial stress, the relative permeability of both phases tends to become equal when the $P_{a} / P_{w}$ ratio is between 1.0 and 1.5. The variation of the relative permeability with the inlet fluid pressure ratio is largely governed by the joint aperture size and the joint surface profile.

For a given confining pressure $(0.5 \mathrm{MPa})$ and inlet water pressure (0.2 MPa), the comparison of single-phase and twophase air flow rates against the inlet air pressure is shown in Fig. 10(a). At a constant cell pressure of $0.5 \mathrm{MPa}$, the air flow rate is reduced by $70 \%$ from the corresponding single-phase flow (compare Curves A and B). At the same confining pressure of $0.5 \mathrm{MPa}$, the water flow rates for a constant air pressure $(0.2 \mathrm{MPa})$ are shown in Fig. 10(b). The two-phase water flow rate is also reduced by $75-85 \%$ for an inlet water pressure range of $0.2-0.3 \mathrm{MPa}$ (compare Curves C and D). Similar to single-phase flow, two-phase flows also follow a linear relationship with inlet fluid pressures for no capillary pressure conditions; hence, the writers' modification of Darcy's equation for two-phase flow [(6)] is justified.

For zero capillary pressure (i.e., $P_{a}=P_{w}=0.2 \mathrm{MPa}$ ), the measured and predicted individual flow rates are plotted in Fig. 11(a). At low confining pressures, the discrepancy between predicted and measured air flow rates is partly attributed to some air probably trapped within the pores of the specimen. With the increase in confining pressure, this trapped air is expected to come out of the pores, thereby giving a much better match with theory.

For fully saturated water flow through rock joints, various studies have shown that the flow rates decrease with the increase in confining pressure due to the closure of apertures (Tsang and Witherspoon 1981; Brown and Scholz 1986). Similar to single-phase flow, two-phase flow is also affected by

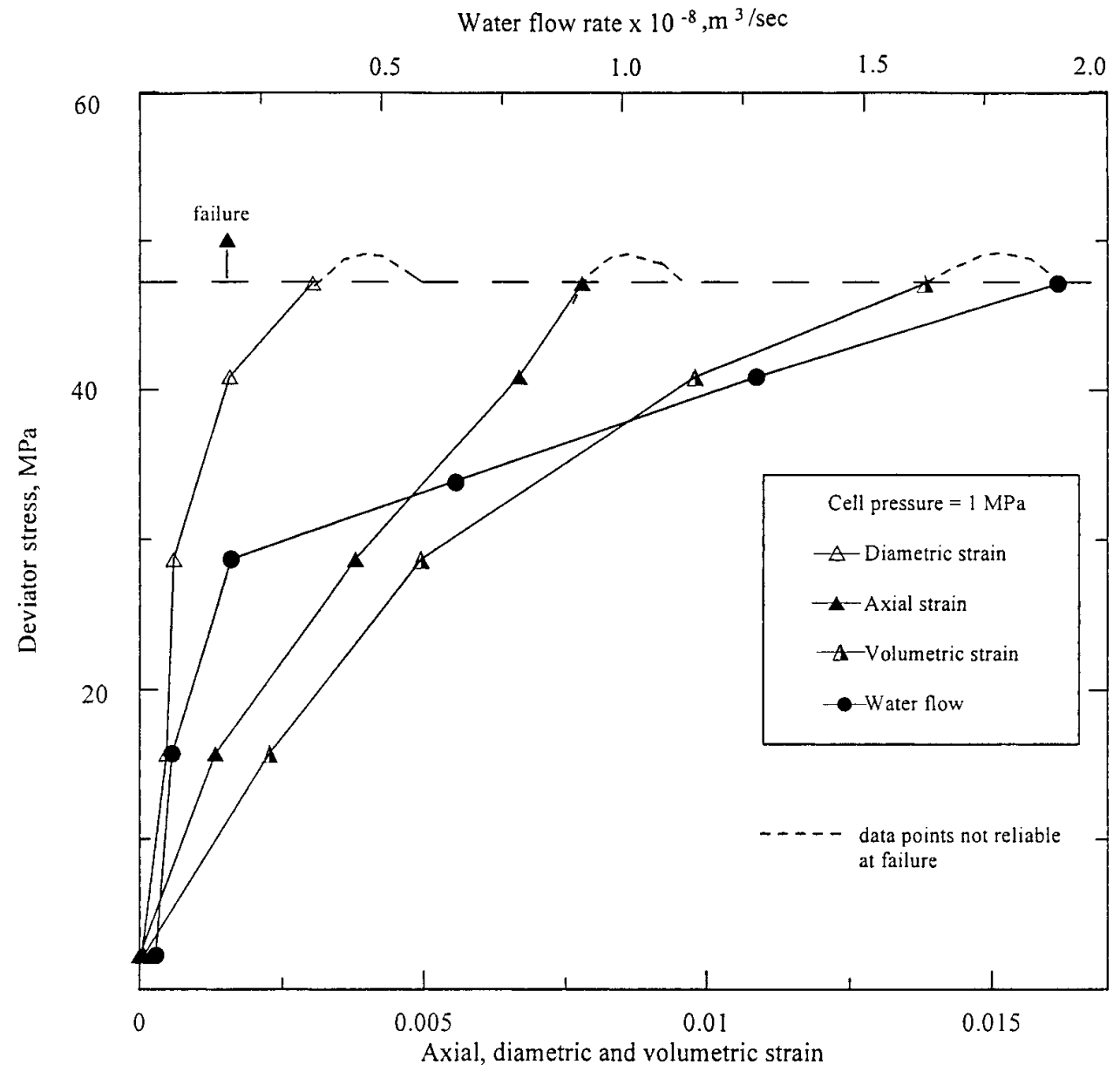

FIG. 12. Relationship of Water Flow and Deformation of Specimen for Different Axial Stress 


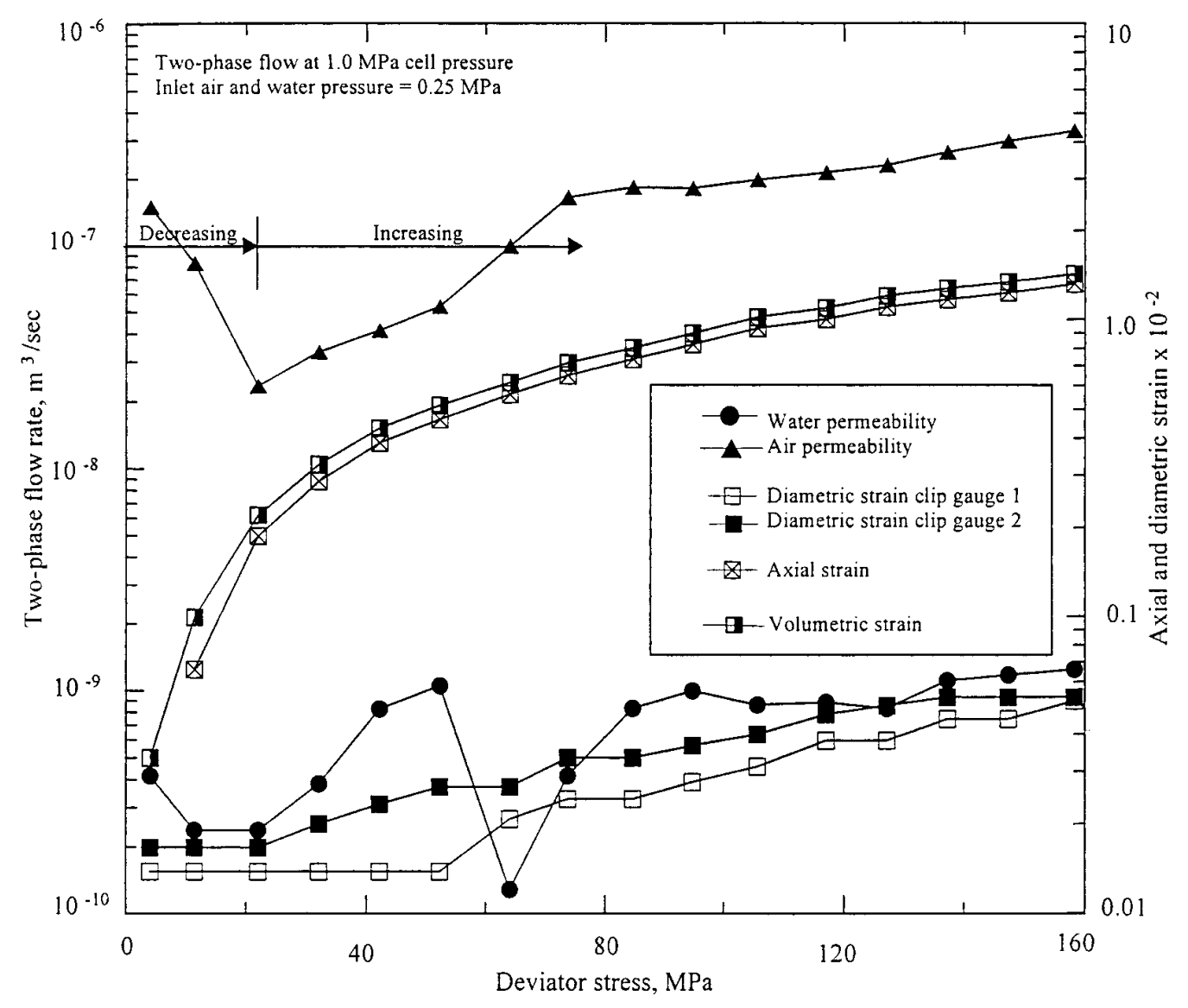

FIG. 13. Relationship of Two-Phase Flow and Deformation of Specimen for Different Axial Stress

the confining pressures in a similar way. For given inlet water and air pressures, the effect of confining pressure on two-phase flow is also illustrated in Fig. 11(a). As expected, flow rates decrease with the increase in confining pressure; however, beyond a confining pressure of $5 \mathrm{MPa}$, the rate of change of flow rate becomes marginal. This can be attributed to joints attaining their residual values. Fig. 11(b) shows that for constant inlet water pressures $\left(P_{w}=0.125,0.2\right.$, and $\left.0.25 \mathrm{MPa}\right)$, the twophase flow rate decreases with the increasing confining pressure, i.e., shift of curves to the right. For a constant confining pressure, when the inlet air pressure $\left(P_{a}\right)$ is increased, the air flow is expected to increase with an associated decrease in the water flow. However, on the contrary, Fig. 11(b) illustrates that the increase in inlet air pressure is associated with a decrease in air flow. This verifies that the increase in confining pressure is more dominant than the role of increasing the inlet air pressure. For instance, at a confining pressure of $0.5 \mathrm{MPa}$ and inlet air pressure of $0.15 \mathrm{MPa}$, the air flow rate is $30 \times 10^{-8} \mathrm{~m}^{3} / \mathrm{s}$. At an increased confining pressure of $2.0 \mathrm{MPa}$ and inlet air pressure of $0.3 \mathrm{MPa}$, the air flow rate is reduced by 30 times to give $1.0 \times 10^{-8} \mathrm{~m}^{3} / \mathrm{s}$. This demonstrates that if the confining pressure is increased considerably, doubling the inlet air pressure has little effect.

Apart from the confining pressure, inlet fluid pressures, and the degree of saturation, the deviator stress $\left(\sigma_{1}-\sigma_{3}\right)$ can also influence the permeability, strength, and deformation properties of the rock specimens. Fig. 12 shows the effect of deviator stress on single-phase water flow, as well as the axial, diametric, and volumetric strains of the specimen at a constant cell pressure of $1 \mathrm{MPa}$. Continuous increase in volumetric strain results in an increased flow through the specimen, either because of the formation of new fractures or dilation of ex- isting fractures or both, especially close to failure $\left(\sigma_{1}-\sigma_{3}>\right.$ $45 \mathrm{MPa}$ ). It is not possible to visually detect fracture propagation, because the cell is constructed of high strength steel. However, the observation of increased flow rates implies either the dilation of existing fractures or the formation of new fractures. Fig. 13 illustrates the variation of two-phase flow rate with the deviator stress at a constant cell pressure of $1 \mathrm{MPa}$. The initial decrease in air and water flow is associated with the closure of joint apertures upon initial loading. However, with increased deviator loading, the air and water flow start to increase, probably due to the dilation of some existing fractures and the formation of new cracks, as also concluded earlier from the data presented in Fig. 12. In Fig. 13, a sudden drop in water flow occurs at a deviator stress of $50 \mathrm{MPa}$, which is accompanied by an increase in air flow, as expected.

\section{SUMMARY AND CONCLUSIONS}

In this paper, a new triaxial equipment for investigating the two-phase intrinsic permeability of fractured granite specimens was introduced, and the associated test results were discussed. From the laboratory test results, the following conclusions can be drawn.

Single-phase flow rates through fractured rock specimens vary linearly against inlet fluid pressures at moderate confining pressures. This is in accordance with the application of Darcy's law for saturated fluid flow through jointed rock mass. In the case of two-phase flow, the approximately linear relationships (when capillary pressure $=0$ ) observed between the individual flow components and the corresponding inlet fluid pressures have influenced the writers to modify the conventional Darcy's law to incorporate the concept of relative permeability, for 
estimating the flow rates of each phase. The relative permeability of air phase increases exponentially with the increase in the $P_{a} / P_{w}$ ratio, while decreasing the relative permeability of water. The opposite trend occurs when the $P_{w} / P_{a}$ ratio is increased.

The writers' mathematical model for two-phase flow rate prediction was based on a simplified stratified flow, following the modified Darcy's law incorporating the relative permeability. The mathematical formulation includes the effect of joint deformation under normal stress, compressibility of air and water, solubility of air and water, and the properties of the joint walls and air-water interface. The individual air and water flow rates through fractured granite specimens measured using the high pressure triaxial apparatus verify the validity of the predictive model. As expected, two-phase flow rates decrease with the increase in confining pressure attributed to joint closure. At elevated confining pressures, the change in individual flow components is marginal, probably due to the joints attaining their residual values. However, it is important to note that the range of confining pressures applied in this study is moderate (1-8 MPa); hence, the findings of this study may not be extrapolated to predict two-phase flow behavior at much greater confining pressures.

During the course of axial loading, permeability of both water and air phases changes continuously. An air-saturated rock matrix would have no water. However, if the rock matrix is saturated with water and the fracture drains, air will easily move through the fracture, but will be blocked from the matrix due to the higher air entry value of the rock matrix. To establish a general theory for two-phase flow through a single rock joint, further laboratory tests should be carried out for an array of jointed rock specimens under a wider range of confining pressure. Particular focus should be given to the evaluation of relative permeability coefficients at elevated confining pressure, considering the relevant applications in the petroleum industry. Although the HPTPTA is mainly designed for handling air and water flow through fractured specimens, it can be modified to include a third fluid phase such as oil (i.e., three-phase flow), which will be most useful in petroleum engineering. In this study, the scope of testing may be further extended to investigate the stress-strain behavior of fractured or porous rocks with multiphase flow under a wide range of confining pressures.

\section{ACKNOWLEDGMENTS}

The writers acknowledge the efforts of Alan Grant (laboratory technician) during the testing program and the financial support given by SCT Pty. Ltd., Wollongong, Australia.

\section{REFERENCES}

Amadei, B., and Illangasekare, T. (1994). "A mathematical model for flow and solute transport in non-homogeneous rock fractures." Int. J. Rock Mech. Min. Sci. and Geomech. Abstr., 31(6), 719-731.
Barden, L., and Pavlakis, G. (1971). "Air and water permeability of compacted unsaturated cohesive soil." J. Soil Sci., 22(3), 302-317.

Brown, S. R., and Scholz, C. H. (1986). "Closure of rock joints." J. Geophys. Res., 91(B5), 4939-4948.

Dusseault, M. B. (1981). "A versatile hollow cylinder triaxial device." Can. Geotech. J., Ottawa, 18(1), 1-7.

Film flow meter-Instruction manual. (1998). STEC Inc., Kyoto, Japan.

Fourar, M., and Bories, S. (1995). "Experimental study of air-water twophase flow through a fracture (narrow channel)." Int. J. Multiphase Flow, 21(4), 621-637.

Fourar, M., Bories, S., Lenormand, R., and Persoff, P. (1993). "Twophase flow in smooth and rough fractures: Measurement and correlation by porous medium and pipe flow models." Water Resour. Res., 29(11), 3699-3708.

Fredlund, D. G., and Rahardjo, H. (1993). Soil mechanics for unsaturated soils, Wiley, New York

Gale, J. E., Rouleau, A., and Atkinson, L. C. (1985). "Hydraulic properties of fractures." Proc., 17th Int. Congr. of Int. Assn. of Hydro., Tucson, Ariz., Vol. 1, 1-16.

Hambly, E. C., and Reik, M. A. (1969). "A new true triaxial apparatus." Géotechnique, London, 19, 307-309.

Hamilton, J. M., Daniel, D. E., and Olson, R. E. (1981). "Measurement of hydraulic conductivity of partially saturated soils." Permeability and groundwater contamination transportation, ASTM Spec. Tech. Publ. 746, T. F. Zimmie and C. O. Riggs, eds., ASTM, West Conshohocken, Pa., 182-196.

Hoek, E., and Franklin, J. A. (1968). "Simple triaxial cell for field or laboratory testing of rock." Trans. Inst. Min. and Metallurgy, Australia, 77(734), A22-A26.

Huang, S., Fredlund, D. G., and Barbour, S. L. (1998). "Measurement of the coefficient of permeability for a deformable unsaturated soil using a triaxial permeameter." Can. Geotech. J., Ottawa, 35(3), 426-432.

Indraratna, B., and Haque, A. (1999). "Triaxial equipment for measuring the permeability and strength of intact and fractured rocks." Géotechnique, London, 49(4), 515-521.

Klute, A. (1965). "Laboratory measurement of hydraulic conductivity of unsaturated soil." Methods of soil analysis, C. A. Black, D. D. Evans, J. L. White, L. E. Ensminger, and F. E. Clark, eds., Monograph 9, Part 1, American Society of Agronomy, Madison, Wis., 253-261.

Lee, C. H., and Farmer, I. (1993). Fluid flow in discontinuities rocks, Chapman \& Hall, London.

Neuzil, C. E., and Tracy, J. V. (1981). "Flow through fractures." Water Resour. Res., 17(1), 191-199.

Priest, S. D. (1993). Discontinuity anlaysis for rock engineering, Chapman \& Hall, London.

Pruess, K., and Tsang, Y. W. (1990). “On two-phase relative permeability and capillary pressure of rough-walled rock fractures." Water Resour. Res., 26(9), 1915-1926.

Rasmussen, T. C. (1991). "Steady fluid flow and travel times in partially saturated fractures using a discrete air-water interfaces." Water Resour. Res., 27(1), 67-76.

Reitsma, S., and Kueper, B. H. (1994). "Laboratory measurement of capillary pressure-saturation relationship in a rock fracture." Water Resour. Res., 30(4), 865-878.

Smart, B. G. D. (1995). "A true triaxial cell for testing cylindrical rock specimen." Int. J. Rock Mech. Min. Sci. and Geomech. Abstr., 32(3), 269-275.

Tsang, Y. W., and Witherspoon, P. A. (1981). "Hydromechanical behavior of deformable rock fracture subject to normal stress." J. Geophys. Res. 86(B10), 9287-9298.

Witherspoon, P. A., Wang, J. S. Y., Iwai, K., and Gale, J. E. (1980),

"Validity of cubic law for fluid flow in a deformable rock fracture." Water Resour. Res., 16(6), 1016-1024. 